\title{
Sürdürülebilir Beslenme ve Beslenme Örüntüsü: Bitkisel Kaynaklı Beslenme
}

\author{
Sustainable Diets and Dietary Pattern: Plant-Based Nutrition
}

\author{
Prof. Dr. Ayla Gülden Pekcan ${ }^{1}$
}

\section{ÖZET}

Sürdürülebilir beslenme yeni bir kavram olmamasına karşın, dünya nüfusunda artış projeksiyonları ve iklim değişikliği konularına artan ilgi sonucunda günümüzde daha fazla dikkat çeker duruma gelmiştir. Gıda Tarım Örgütü (FAO) ve Dünya Sağllk Örgütü (WHO) sürdürülebilir sağllklı diyeti "Sürdürülebilir diyetler çevresel etkisi düşük olan, besin ve beslenme güvencesini ve günümüz ve gelecek nesiller için sağllkl yaşamı destekleyen diyetlerdir” diye tanımlamaktadır. Sürdürülebilir diyetler insan ve doğal kaynakları optimize ederken; biyoçeşitliliğe ve ekosisteme saygılı ve koruyucu, kültürel olarak kabul gören, erişilebilir, ekonomik olarak uygun ve karşılanabilir, beslenme açısından yeterli, güvenilir ve sağlıklı diyetlerdir. Besin üretimi ve tüketimi çevresel bozulmanın temel etmenleri arasındadır. Günümüzde küresel besin sisteminin sürdürülebilir olmadığı dikkati çekmektedir. Küresel olarak üretilen besinlerin üçte biri israf edilmekte veya kayba uğramaktadır. Optimal ve sürdürülebilir sağlık yaşam döngüsü sürecinde sürdürülebilir beslenme örüntüsü ile olasıdır. Bunun da bitkisel kaynaklı beslenme ile olasılığı rapor edilmektedir. Diyetisyenlerin mesleki eğitim ve öğretim programında sürdürülebilir beslenme, sürdürülebilir sağlık ve sürdürülebilir çevre yaklaşımları yer almalı, diyetisyenler varlıklarını görünür kılmalı, becerilerini pekiştirmeli ve sürdürülebilirlik okuryazarı ve savunucusu olmalıdır.

Anahtar kelimeler: Sürdürülebilir beslenme, bitkisel kaynaklı beslenme, diyetisyen

\begin{abstract}
The concept of sustainable diets, although not new, is gaining increased attention across the globe, especially in relation to projected population growth and growing concerns about climate change. As defined by the FAO "Sustainable diets are those diets with low environmental impacts which contribute to food and nutrition security and to healthy life for present and future generations". Sustainable diets are protective and respectful of biodiversity and ecosystems, culturally acceptable, accessible, economically fair and affordable; nutritionally adequate, safe and healthy, while optimizing natural and human resources. Food production and consumption are among the main drivers of environmental degradation. Globally, a third of the food produced is lost or wasted. Optimal (healthy) nutrition is possible with a sustainable dietary pattern. It is reported that it could only be sustained by plant-based diets. In the professional educational curricula of the dietitian, sustainable nutrition, sustainable health and sustainable environment approaches should include and dietitians need to amplify their visibility, consolidate their skills and become more sustainability literate and advocates.
\end{abstract}

Key words: Sustainable diets, plant-based nutrition, dietitian

1. Hasan Kalyoncu Üniversitesi, Sağllk Bilimleri Fakültesi, Beslenme ve Diyetetik Bölümü, Gaziantep, Türkiye, Türkiye • E-posta: info@beslenmevediyetdergisi.org 으 https://orcid.org/0000-0002-2037-3037 


\section{GİRIŞ}

Sürdürülebilir sağlıklı diyetler bireyin sağlığını ve iyilik halini tüm yönleri ile geliştiren, düşük çevresel baskısı ve etkisi olan, erişilebilir, maliyeti karşılanabilir, güvenilir, eşitlikçi ve kültürel olarak kabul edilebilir beslenme örüntüleridir. Hedefi tüm bireylerin optimal büyüme ve gelişmesini sağlamak, günümüz ve gelecek nesillerin tüm yaşam sürecinde fiziksel, mental ve sosyal yönden iyilik halini ve işlevselliğini geliştirmek, malnütrisyonun her türünün (yetersiz beslenme, mikrobesin ögeleri eksikliği, fazla kilo, şişmanlık) önlenmesine katkı sağlamak, beslenmeye bağlı bulaşıcı olmayan hastalıkların $(\mathrm{BOH})$ riskini azaltmak, biyoçeşitliliğin ve gezegenin korumasını desteklemektir. Sürdürülebilir sağlıklı diyet sürdürülebilirliğin tüm boyutlarını birleştirerek istenmedik sonuçları önleyici olmalıdır (1).

\section{Sürdürülebilir Beslenme, Besin Sistemi ve Küresel Beslenme Sorunları}

Sürdürülebilirlik kavramı ilk kez Birleşmiş Milletler bünyesinde çalışan Dünya Çevre ve Kalkınma Komisyonu'nun (WCED) 1987 yılında yayımladığı "Ortak Geleceğimiz" isimli rapor ile ele alınmıştır. Raporda "İnsanlık, doğanın gelecek kuşakların gereksinimlerine cevap verme yeteneğini tehlikeye atmadan, günlük ihtiyaçları sağlayabilme ve kalkınmayı sürdürülebilir kılma yeteneğine sahiptir" denilmektedir (2). Gida ve Tarım Örgütü (FAO) "Sürdürülebilir beslenme; insan ve doğal kaynakları optimize etme yanında, biyoçeşitliliğe ve ekosisteme saygll ve koruyucu, kültürel olarak kabul gören, ulaşllabilir, ekonomik olarak uygun ve karşılanabilir, beslenme açısından yeterli, güvenilir ve sağlıklıdır” demektedir $(1,3,4)$. FAO, 2050 yllında artan dünya nüfusunun gereksinmesinin ve artan hayvansal besine talebin karşllanabilmesi için besin üretiminde en az \%62 artış sağlanmasının gerekli olduğunu belirtmiştir (5).

Besin sistemlerinin insan sağlığını koruma ve çevrenin sürdürülebilirliğini destekleme potansiyeli bulunmaktadır. Günümüzde besin sistemleri bazı etmenlerle engellenmektedir. Artan küresel nüfus için sürdürülebilir besin sistemlerinden sağlıklı beslenmeye erişimde acil önlemlere gerek olduğu belirtilmektedir. Besin üretimi ve tüketimi çevresel bozulmanın temel nedenleri arasındadır. Küresel olarak üretilen besinin üçte biri israf edilmekte veya kayba uğramakta, atılmaktadır. Sağlıksız ve sürdürülebilir olmadan üretilen besinler yeryüzü ve insanlar için risk oluşturmaktadır (6). Besin üretimi küresel çevre değişiminin en büyük nedenidir. Tarımın küresel toprak kullanımının \%48'ini kapsadığı ve besin üretiminin küresel sera gazı salınımımın yaklaşık \%30'undan (\%20-35) ve temiz su kullanımının \%70'inden sorumlu olduğu belirtilmektedir $(1,7,8)$.

Sağlıksız ve sürdürülebilirliği olmayan besin üretimi insan sağlığı ve dünya için küresel risk oluşturmaktadır. Dünya'da 820 milyondan fazla insanın her gece yatağa aç girdiği (1) ve yetersiz beslendiği (9), 2018 yılında 1.3 milyar kişinin orta düzeyde gıda güvencesizliği yaşadığı; yani düzenli olarak besleyici ve yeterli besine erişemediği (1), 151 milyon çocuğun yaşına göre boy uzunluğunun kısa (bodur), 51 milyon çocuğun boy uzunluğuna göre vücut ağırlığının düşük (zayıf) (10) 2 milyardan fazla insanın mikrobesin ögeleri eksikliğinin (11) olduğu bilinmektedir. Fazla kilo ve şişmanlık ile BOH'lar küresel olarak 4 milyon ölüme neden olmaktadır. Günümüzde yaklaşı 2 milyar yetişkin ve 40 milyondan fazla beş yaş altı çocuk fazla kiloludur. 670 milyondan fazla yetişkin ve 120 milyondan fazla 5-19 yaş grubu çocuk ve genç ise şişmandır (1). Son 30 yılda diyabetin küresel prevalansında iki kat artış olduğu rapor edilmiştir $(12,13)$.

Küresel veriler doğrultusunda 2017 yllında 11 (10-12) milyon ölüm (yetişkinlerde tüm ölümlerin \%22'si) ve 255 (234-274) milyon sağlıklı yaşam yılı kaybı (DALY) (yetişkinlerde tüm DALY’nin \%15’i) diyet risk etmenlerine bağlı olarak görüldüğü belirlenmiştir. Diyete bağlı ölümler ile DALY için ilk sirada kardiyovasküler hastalıklar (KVH) (ölüm: 10 milyon, DALY: 207 milyon) yer almakta, bunu kanserler (ölüm: 
913 090, DALY: 20 milyon) ve tip 2 diyabet (ölüm:338 714, DALY: 24 milyon) izlemektedir. Beş milyondan fazla ölüm (\%45) ve 177 milyon DALY (\%70) 70 yaş öncesi yaş grubunda görülmektedir (14).

Malnütrisyonun nedenleri karmaşıktır. Sağlıksız beslenme küresel olarak en temel düzeltilebilir risk etmenidir, küresel hastalık yükünün temel nedenlerindendir ve 2016 yllında DALY ve ölümler için ikinci sırada risk etmeni olarak belirlenmiş, 2017 yllında ise yaklaşık 11 milyon ölüm ve 255 milyon DALY'den sorumlu bulunmuştur (1). Malnütrisyonun önlenmesi için beslenmenin iyileştirilmesi ve geliştirilmesi gerekmektedir. $\mathrm{Bu}$ doğrultuda şehirleşme, pazarın ve ticaretin küreselleşmesi, gelir düzeyi, süpermarket ve büyük besin pazarlama sistemlerinin oluşması sorunlara katkı sağlamaktadır. Beslenmeyi iyileştirmek için besinin üretimi, işlenmesi ve paketlenmesi, dağıtımı, pazarlanması, tüketimi ve besinin israfı ve kaybı gibi, kısaca tarladan sofraya tüm var olan besin sisteminin ele alınması gerekmektedir (1).

Optimal (sağlıklı) beslenme; yaşam döngüsü sürecinde sürdürülebilir beslenme örüntüsü ile olasıdır. Dünya Sağlık Örgütü (WHO) bulaşıcı olmayan kronik hastalıkların (BOH) küresel olarak ölümlerin ilk ve önde giden nedeni olduğunu belirtmekte ve altı WHO bölgesi içerisinde Avrupa Bölgesi'nin BOH'tan en fazla etkilenen bölge olduğunu rapor etmiştir. Avrupa Besin ve Beslenme Eylem Planı 2015-2020 ile Avrupa Bölgesi'nde beslenmeye bağll önlenebilir BOH'un ve sık görülen her türlü malnütrisyonun azaltılmasını tüm hükümetler kapsamında, tüm politikalarda sağlık yaklaşımı doğrultusunda hedeflemektedir. Besin sistemlerinin yönetiminin, toplumun diyetinin ve beslenme durumunun iyileştirilmesine katkı sağlayacak bir dizi öncelikli eylemler sunmuştur. Çalışmaların sonucunda Akdeniz Diyeti (AD) ve Nordik Diyeti (ND) (İskandinav ülkeleri: Danimarka, Finlandiya, İzlanda, Norveç, İsveç) olarak iki Avrupa diyetinin sağllğı geliştirici olduğu rapor edilmiştir (15).

\section{Sürdürülebilir Beslenme Modelleri: Akdeniz ve Nordik Diyetleri}

Akdeniz Diyeti (AD) sürdürülebilir diyet örüntüsü olarak tanımlanmakta, sağlığın iyileştirilmesi ve geliştirilmesi, hastalıkların önlenmesi için izlenmesi gereken bir beslenme örüntüsü olarak önerilmektedir. AD’i temelde bitkisel besin tüketimine dayalıdır. Bitkisel kaynaklı besinlere dayalı olması iklim değişikliğinin önlenmesi ve su ayak izinin azaltılması açısından önem taşımaktadır. AD’nin dört sürdürülebilir yararı vurgulanmaktadır. Bunlar; 1) sağlık ve beslenme yararları, 2) düşük çevresel etkisi ve biyoçeşitlilik zenginliği, 3) yüksek sosyokültürel besin değerleri ile kültürel miras oluşu ve 4) olumlu yerel ekonomik geri dönüşümüdür (3).

Akdeniz Diyeti Kuruluşu (Mediterranean Diet Foundation) 2011 yllında güncellenmiş Akdeniz Diyet Piramidini yayınlamıştır. $\mathrm{AD}$ örüntüsünün bitkisel kaynaklı besinler (meyve, sebze, sert kabuklu yemişler ve tahıllar) ile zeytinyağının fazla; balık ve tavuk etinin orta; süt ve ürünleri (özellikle yoğurt ve peynir olarak), kırmızı et, işlenmiş et ve tatlıların (yerine sıklıkla taze meyvenin tüketildiği) az miktarda tüketildiği bir beslenme şeklidir. Normal koşullarda yemekle birlikte orta düzeyde şarap (Türkiye'de şıra ve hardaliye gibi içecekler) tüketimine dayalı olduğu ve ülkelere göre bazı farklılıkların da olabileceği belirtilmektedir (3,16). Geleneksel AD sosyal ve kültürel etmenlerle yakından ilişkilidir. Örneğin; yemekte aile birlikteliği, öğlen yemeği sonrası kısa süreli uyku (siesta), uzun yemek yeme süresi gibi özelliklerin de sağlık üzerine olumlu etkiler yaptığı belirtilmektedir. UNESCO (United Nations Educational, Scientific and Cultural Organization's Representative) 2010 yllında AD’yi “Maddi Olmayan Kültürel Miras” listesine almıştır (16).

$\mathrm{AD}$ tüm nedenlere dayalı ölümlerle ters yönde ilişkili bulunmuştur (17,18). Diğer sağlık yararları ise kanser $(19,20)$, bilişsel hastalıklar $(21,22)$, KVH (23-25), metabolik sendrom, obezite ve tip 2 diyabet (26-29) riskini azaltmasıdır. Vücut ağırlık kaybının yönetiminde de yararlar sağlamaktadır (30). AD 
hastalıkların önlenmesi, azaltılması ve tedavisi için önem taşımaktadır (18).

Nordik Diyeti (ND) 2004 yılında bir grup araştırmacı, diyetisyenler ve hekimler tarafindan Michelinyıldızlı Kopenhag'da bulunan NOMA adlı restoranın işbirliğinde Baltık Deniz Diyet Piramidi'nden uyarlanarak Nordik ülkeleri halkını daha fazla taze, mevsimsel ve yerel besinler yemelerini desteklemek üzere geliştirilmiştir. ND’in sağlık yararları üzerinde çalışmalar yürütülmüştür. ND dört temel özelliğe sahiptir. Bunlar; sağlık, gastronomik güç, sürdürülebilirlik ve Nordik kimliğidir (15,31). Dünya'nın diğer ülkelerinde olduğu gibi bireylerin kırmızı et ağırlıklı işlenmiş, paketlenmiş Batı diyeti tüketmesi sonucunda obezite hızlarının artması sonucu bu yaklaşım sergilenmiştir. ND taze, yerel meyveler ve sebzeler, deniz ürünleri ve tam tahıllara dayalı bir diyettir. ND’inde ki temel besin bileşenlerini üzümsü meyveler ile diğer meyveler, yağlı balıklar (ringa, orkinos, somon), yağsız balık, kurubaklagiller, sebzeler (lahana ve kök sebzeler) ve tam tahıllar (arpa, yulaf, çavdar) oluşturmaktadır. ND ve AD arası temel farklılık zeytinyağı yerine kolza (kanola) yağının kullanılmasıdır (32-34). ND, Güney ülkeler ikizi olan Akdeniz diyeti (AD) ile Okinawa diyetinde de olduğu gibi benzerlikleri kendi bölgesel özellik ve yetenekleri doğrultusunda paylaşmaktadır (31).

ND’in kardiyovasküler hastalık riskini azalttığı $(35,36)$, hiperkolesterolemik bireylerdelipit profili, kan basıncı ve insülin duyarlılığı üzerinde olumlu etkilerinin olduğu $(32,37)$, tip 2 diyabetin önlenmesi $(34,38)$, abdominal yağlanması olan erkek ve kadınlarda vücut ağırlık kaybı sağladığı (39) bulunmuştur. Uzun dönemde ND’e uyumun tip 2 diyabet üzerine etkilerinin belirlenebilmesi için daha geniş kapsamlı prospektif araştırmaların yürütülmesinin gerektiği de belirtilmektedir (34).

\section{Birleşmiş Milletler Sürdürülebilir Kalkınma Hedefleri}

Günümüzde insan sağllğı ve çevresel sürdürülebilirlik için temel küresel hedeflerin varlığı dikkati çekmektedir. Ülkelerin beslenme örüntüsünde değişim, dünya nüfusunun 2050 yılında 10 milyar olacağı, küresel ısınmanın $2^{\circ} \mathrm{C}$ artacağı projeksiyonları sonucunda insanlar ve dünya için büyük riskler oluşacağı bildirilmektedir. Ayrıca, beslenmeye bağlı bulaşıcı olmayan hastalıkların daha da artacağı, besin üretimi etkisi ile sera gazı salınımı, azot ve fosfor kirliliği, biyoçeşitlilik kaybı, su ve toprak kullanımının dünya sisteminin durağanlığını bozacağı, besin üretiminin etkileneceği de ileri sürülmektedir (6). "Birleşmiş Milletler Sürdürülebilir Kalkınma Hedefleri, 2030 (UN Sustainable Development Goals SDGs)" ile yoksulluğun ortadan kaldırılması, gezegenin korunması, herkes için refahın sağlanması, açlığın ve kötü beslenmenin yok edilmesi hedeflenmiştir. $\mathrm{Bu}$ uluslararası politika çerçevesi insan sağlığını veya çevresel sürdürülebilirliği birçok hedefinde içermektedir (10). Paris Antlaşması (Paris Agreement) iklim değişikliğine odaklanmasına karşın, iklim değişikliğinin insan sağlığı üzerine etkisini de ele almaktadır. Paris Anlaşması ile küresel ısınmayı $2^{\circ} \mathrm{C}$ 'nin altında tutmak, $1.5^{\circ} \mathrm{C}$ 'yi hedeflemek sadece küresel enerji sistemlerinin dekarbonize edilmesi (karbonun ayrılması) ile olası görülmemektedir. Negatif salınım sağlayan besin sistemlerine geçiş ve doğal ekosistemlerde karbon havuzunun önlenmesi temel ulaşılması gereken hedeflerdir (40).

Birleşmiş Milletler Sürdürülebilir Kalkınma Hedefleri ve Paris Antlaşması'na ulaşabilmek için sürdürülebilir besin sistemleri ile sağlıklı beslenmenin sağlanması ve bu dönüşüm için bilimsel sağllklı beslenme hedeflerinin sürdürülebilir besin üretiminin sağlanmasına rehberlik edilmesi gerekmektedir. Sağlıklı beslenme için uygun enerji alım miktarı bellidir. Bitkisel besine dayalı besin çeşitliliğini içeren, hayvansal kaynaklı besinlerin az, doymuş yağlar yerine doymamış yağların tüketildiği, ayrıca rafine tahılların, aşırı işlenmiş besinlerin ve eklenmiş şekerin az tüketildiği bir beslenme örüntüsü sağlıklı beslenme olarak tanımlanmaktadır. Sürdürülebilir besin sistemlerinin güvenilir şekilde yönetilebilmesi için altı adet anahtar dünya sistem süreci dikkati çekmektedir. Besin üretimi küresel çevre değişiminde 
en büyük etkendir, iklim değişikliği, biyoçeşitlilik kaybı, temiz su kullanımı, küresel azot ve fosfor döngüsü, toprak-sistem değişikliği (ve kimyasal kirlenme) gibi etmenlere neden olmaktadır. Küresel besin sistemlerinin 2015 yll ve sonrası için herkese kazan-kazan (yani sağlıklı ve çevresel olarak sürdürülebilir) diyetler sağlayabileceği de belirtilmektedir (6).

\section{Bitkisel Kaynaklı Beslenme ve Bilimsel Kanıta Dayalı Veriler}

Optimal beslenme beklenen yaşam süresi artışı, yaşam sürecinde tüm kronik hastalık risklerinin azalması ve gen ekspresyonunun iyileştirilmesi ile ilintilidir. Minimal düzeyde işlenmiş ve doğaya oldukça yakın, çoğunlukla bitkisel besin kaynaklı beslenmenin sağlığı iyileştirici ve geliştirici olduğu kanıta dayalı verilerle vurgulanmaktadır (41).

Birleşmiş Milletler Sürdürülebilir Kalkınma Hedefleri 2030 ve Paris Antlaşması erişebilmek için küresel hedefler doğrultusunda hangi besin üretimi ve hangi diyetler konusunda çalışmalar yürütülmektedir. Dikkat çeken çalışmalardan biri 16 Ocak 2019 (düzeltilmiş yayın: 7 Şubat 2019) tarihinde "Lancet" dergisinde Willett ve ark. (6) tarafindan "Food in the Anthropocene: the EAT-Lancet Commission on healthy diets from sustainable food systems" konu başlı̆̆ ile yayınlanmıştır. Çalışma 16 ülkeden insan sağlığı, tarım, politik bilimler, çevresel sürdürülebilirlik alanlarında uzman 37 kişi tarafından yürütülmüştür. Çalışmanın amacı ise; "Kanıta dayalı olarak sağlıklı diyet ve sürdürülebilir gıda üretimi için küresel bilimsel hedefler belirlemek, besin sisteminde (üretimden tüketime) Sürdürülebilir Kalkınma Hedefleri'ne (SGD) ve Paris Antlaşması ilkelerine ulaşmayı sağlayacak diyet ve besin üretim uygulamalarını tanımlamaktır”. Antroposen, jeolojik çağdır ve Dünya'daki değişimin hakim yöneticisi olan insanlık ile karakterizedir. Antroposende besin 21. yüzyllda en büyük sağlık ve çevresel zorluklardan birini temsil etmektedir (6). Sözcük anthropo (insan) ve -cene (yeni, çağ) kelimelerinden türetildiği ve dünyanın şu anda içinde olduğu çağı tanımladığı bilinmektedir.
EAT-Lancet çalışmasında komisyon, günümüzde uygulanan ve çoğunlukla sağlıksız besinlere dayalı standart diyetlerin yerine sağlık ve çevresel etki temeline dayalı küresel sağlıklı referans bir diyet tanımlamıştır. Hazırlanan sağlıklı referans diyet 2500 kkal içermektedir. $\mathrm{Bu}$ enerji miktarı 30 yaşında $70 \mathrm{~kg}$ bir erkeğin ve 30 yaşında $60 \mathrm{~kg}$, orta ve yüksek fiziksel aktivitesi olan bir kadının enerji gereksinmesini karşllayabilmektedir. Komisyonun kanıta dayalı bilimsel hedeflere göre belirlediği sağlıklı referans diyet; çoğunlukla sebze, meyve, tam tahıl, kurubaklagiller, sert kabuklu yemişleri, az miktarda doymamış yağları, orta düzey miktarlarda deniz ürünleri ve kümes hayvanları içermekte; kırmızı et, işlenmiş et, eklenmiş şeker, rafine tahıl ve nişastalı sebzeleri ise az ya da hiç içermemektedir. Sağlıklı referans bir diyet için besinlerin günlük önerilen alım miktarları; tam tahıl 232 g (811 kkal); yumru ve nişastall sebzeler $50 \mathrm{~g}$ (39 kkal); toplam sebze 300 g (100 gramı yeşil yapraklı, 78 kkal); meyve 200 g (126 kkal); süt ve ürünleri (örn. peynir) $250 \mathrm{~g}$ (153 kkal); protein kaynakları olarak kırmızı et $14 \mathrm{~g}$ (30 kkal), tavuk ve diğer kümes hayvanları 29 g (62 kkal), yumurta 13 g (19 kkal) ve balık 28 g (40 kkal); kurubaklagiller 75 g (284 kkal), yağlı tohum 25 g (142 kkal), sert kabuklu yemiş 25 g (149 kkal); eklenmiş yağ (sıvı yağ dahil) 52 g (450 kkal), eklenmiş şeker $31 \mathrm{~g}$ (120 kkal) olarak önerilmiştir (6).

Hirvonen ve ark. (42) EAT-Lancet yayınını dikkate alarak 159 ülkede 2011 yllı için 744 besinin satış fiyatlarını incelemiştir. EAT-Lancet diyetinin en karşlanabilir günlük küresel maliyetinin medyan değeri 2.84US\$ (Güven aralığı: 2.41-3.16) bulunmuştur. En yüksek maliyet payını sebze ve meyve (\%31.2) alırken, bunu kurubaklagil ve sert kabuklu yemişler (\%18.7), et-yumurta ve balık (\%15.2), sütve ürünlerinin (\%13.2) izlediği belirlenmiştir. Bu diyetin fakir ülkelerde karşılanamayacağı da belirtilmiştir. EATLancet diyetin besin ögesi yeterliliği için minimum maliyet 1.60 faktöründe pahalı bulunmuştur. Birçok ülke için diyetin karşılanabilmesinde, gelirde artışın sağlanmasının, beslenme desteği ile düşük besin ücretinin sağlanmasının gerekliliği vurgulanmıştır. 
Literatür taraması yapıldığında $\mathrm{BOH}$ riski ile besin grupları arasında ilişkiyi gösteren birçok metaanaliz ve sistematik derleme yayına ulaşabilmek olasıdır. Suboptimal diyetin bulaşıcı olmayan (kronik) hastalıklar için önemli önleyici etmen olduğunun belirtildiği Küresel Hastalık Yükü 2017 sistematik analiz çalışması yayınlanmış ve besinlerin günlük önerilen optimal alım miktarları rapor edilmiştir (14). Çalışma 1980-2016 yılları arasında195 ülkede yürütülmüş olan 24-saatlik besin tüketim verileri, 15 besin ve besin ögesinin incelenmesi ile irdelenmiş ve bulaşıcı olmayan hastalıklara bağlı (BOH) mortalite ve morbiditenin değerlendirilmesi amaçlanmıştır. Ölümlerin \%50'sinin ve DALY'nin \%66'sının diyet risk etmenlerine bağll görüldüğü rapor edilmiştir. Yapılan çalışmada birçok ülke için en önemli diyet risk etmenleri olarak ilk sırada yüksek sodyum alımı (ölüm: 3 [1-5] milyon, DALY: 70[34-118] milyon), düşük tam tahıl (ölüm: 3 [1-5] milyon, DALY: 70 [34118] milyon) ve düşük meyve tüketimi (ölüm: 2 [1-4] milyon, DALY: 65 [41-92] milyon) belirlenmiştir. Bunu diyette sert kabuklu meyveler ile yağlı tohumlar, sebze, omega 3 içeren deniz ürünleri, posa, çoklu doymamış yağ asitleri, kurubaklagiller, kalsiyum, süt tüketiminin düşük oluşu ve trans yağların, şekerle tatlandırılmış içeceklerin, işlenmiş et ve kırmızı et tüketimin yüksek oluşu izlemiştir. Çalışmada Türkiye verileri de incelenmiş ve ölümlerin \%42'sinin, DALY'nin \%44'ünün kardiyovasküler hastalıklara (KVH) bağlı olduğu, KVH'ın diğer ülkelere kıyasla Türkiye'de daha düşük oranlarda görüldügü ve tam tahıl tüketiminin düşük olmasının en önemli diyet risk etmeni olduğu belirtilmiştir. Sonuçta ülkelerde kanıta dayalı diyet müdahalelerinin uygulanmasinın gerekliliği önerilmiştir. Ülkelerden elde edilen bulgular doğrultusunda diyetle enerji alımı 2000 kkalori olarak standardize edilmiş ve diyetle 15 besin grubundan diyetle optimal alım miktarları 25 ve üzeri yaş grubu için 1990-2017 yılları arasında yürütülen besin tüketim araştırmalarına dayalı olarak (veri temsiliyeti \%94.9 düzeyinde) belirlenmiştir. Günlük önerilen optimal alım miktarları meyve (250 g), sebze (360 g), kurubaklagil (60 g), tam tahll (125 g), sert kabuklu yemiş ve yağlı tohum (21 g), süt (435 g), kırmızı et (23 g), işlenmiş et ( $2 \mathrm{~g}$ ), şekerle tatlandırılmış içecek (3 g), posa (24 g), kalsiyum (1250 mg), deniz ürünleriomega 3 yağ asitleri (250 mg), çoklu doymamış yağ asitleri (enerjinin \%11'i), trans yağ asitleri (enerjinin \%0.5’i) ve sodyum (3000 mg) için belirlenmiştir (14).

EAT-Lancet Komisyonu (6) ve GBD 2017 (14) tarafindan önerildiği gibi Sağlıklı Referans Diyet’in yaklaşımını Akdeniz ile Nordik Diyetlerin karşıladığı ve bu kapsamda bitkisel kaynaklı beslenmenin son yıllarda bulaşıcı olmayan hastalıkların önlenmesinde birçok meta-analiz ve sistematik derleme ile irdelendiği görülmektedir.

Son ylllarda besin gruplarının tüm nedenlerle ölümler ve hastalık riskleri arasındaki ilişkileri irdelemek üzere birçok sistematik derleme ve meta-analiz çalışması yayınlanmıştır. Bu yayınlarda sıklıkla 12 temel besin grubunun tüketimi (tam tahıllar, rafine tahıllar, sebzeler, meyveler, sert kabuklu yemişler, kurubaklagiller, yumurta, süt ve ürünleri, balık, kırmızı et, işlenmiş et, şekerle tatlandırılmış içecekler) ile ilintili bilgilerle tüm nedenlerle ölümler ve hastalık riskleri arası ilişkilerin incelendiği görülmektedir. Bu yayınların bazıları aşağıda özetlenmiştir.

Schwinghackl ve ark. (43) yaptıkları sistematik derlemede 12 temel besin grubunun tüketimi (tam tahillar, rafine tahıllar, sebzeler, meyveler, sert kabuklu yemişler, kurubaklagiller, yumurta, süt ve ürünleri, balık, kırmızı et, işlenmiş et, şekerle tatlandırılmış içecekler) ile tüm nedenlerle ölümler arası ilişkiyi incelemişlerdir. Sonuçta lineer dozyanıt meta-analizi sonuçlarına göre; tüm nedenlerle ölümlerin tam tahıl (RR: 0.92), sebze (RR: 0.96), meyve (RR: 0.94), sert kabuklu yemiş (RR: 0.76) ve balık (RR: 0.93) tüketiminde (her bir servis miktarı) günlük tüketiminde artış ile azaldığı, kırmızı et (RR: 1.10; 95\% CI: 1.04, 1.18) ile işlenmiş etin (RR: 1.23) günlük tüketiminde (her bir servis miktarı) artış ile ise arttı̆̆ı rapor edilmiştir. Tüm nedenlerle ölümlerde, riski azaltan besinlerin tüketimi ile \%56 azalmanın, riski arttıran besinlerin tüketimi ile ise 2 kat artışın olduğu belirlenmiştir. 
Bechthold ve ark. (44) yaptıkları sistematik derlemede 12 temel besin grubunun tüketimi (tam tahıllar, rafine tahıllar, sebzeler, meyveler, sert kabuklu yemişler, kurubaklagiller, yumurta, süt ve ürünleri, balık, kırmızı et, işlenmiş et, şekerle tatlandırılmış içecekler) ile koroner kalp hastalığı (KKH), inme ve kalp yetmezliği (KY) arası ilişkiyi incelemişlerdir. Sonuçta lineer doz-yanıt meta-analizi ile tam tahıllar $\left(\mathrm{RR}_{\mathrm{KKH}}: 0.95 ; \mathrm{RR}_{\mathrm{KY}}: 0.96\right)$, sebze ve meyveler $\left(\mathrm{RR}_{\mathrm{KKH}}: 0.97\right.$ ve $0.94 ; \mathrm{RR}_{\mathrm{INME}}: 0.92$ ve 0.90 ), sert kabuklu yemişler $\left(\mathrm{RR}_{\mathrm{KKH}}: 0.67\right)$ ve balık $\left(\mathrm{RR}_{\mathrm{KKH}}: 0.88\right.$; $\mathrm{RR}_{\mathrm{INME}}: 0.86 \mathrm{ve} \mathrm{RR}_{\mathrm{KY}}$ : 0.80) tüketimi arasında ters yönde ilişki belirlenirken, yumurta $\left(\mathrm{RR}_{\mathrm{KY}}: 1.16\right)$, kirmızl et $\left(\mathrm{RR}_{\mathrm{KKH}}: 1.15\right.$; $\mathrm{RR}_{\mathrm{INME}}$ : 1.12; $\left.\mathrm{RR}_{\mathrm{KY}}: 1.08\right)$, işlenmiş et $\left(\mathrm{RR}_{\mathrm{KKH}}: 1.27 ; \mathrm{RR}_{\mathrm{INME}}: 1.17\right.$, $\left.\mathrm{RR}_{\mathrm{KY}}: 1.12\right)$ ve şekerle tatlandırılmış içecek $\left(\mathrm{RR}_{\mathrm{KKH}}: 1.17\right.$; $\left.\mathrm{RR}_{\mathrm{INME}}: 1.07 ; \mathrm{RR}_{\mathrm{KY}}: 1.08\right)$ tüketimi ile pozitif ilişkinin olduğu saptanmıştır. Tam tahıl (yaklaşık 100 g/gün, \%17 azalma), meyve (yaklaşık 200 g/gün, \%15 azalma), sert kabuklu yemiş (yaklaşık 10-15 g/gün, \%21 azalma), süt ve ürünleri (yaklaşık $500 \mathrm{~g} / \mathrm{gün}, \% 5$ azalma) ve kırmızı et (yaklaşık 100 g/gün, \%10-20 artma) tüketimi ile KKH arasında lineer olmayan doz-yanıt ilişkisi net olarak belirlenmiştir. Tam tahıl, sebze, meyve, sert kabuklu yemiş, kurubaklagil, süt ve ürünleri, balık, kırmızı et, yumurta ve şekerle tatlandırılmış içecek tüketiminin optimal alımının KKH, inme ve koroner yetmezlik riskinde düşüş olacağı saptanmıştır.

Schwingshackl ve ark. (45) yaptıkları sistematik derlemede 12 temel besin grubunun tüketimi ile tip 2 diyabet (T2D) riski arası ilişkiyi incelemişlerdir. Lineer doz-yanıt meta-analizinde 12 besin grubundan 6’sının T2D riski ile önemli ilişki gösterdiği, bunlardan 3 besin grubunun (tam tahıl, meyve ve süt ve süt ürünleri) tüketimi arttığında riskin düştüğü, diğer 3 tanesinin (kırmızı et, işlenmiş et, şekerle tatlandırılmış içecek) tüketimi arttığında ise T2D riskinin de arttığı bulunmuştur. Lineer-olmayan kanıt ilişkisi ise T2D ile meyve, sebze, işlenmiş et, tam tahıl ve şekerle tatlandırılmış içecekler arasında belirlenmiştir. Riski azaltan besinlerin optimal tüketimi ile riskte \%42 azalma ve riski arttıran besinlerin tüketimi hiç tüketmeyenlerle kıyaslandığında ise T2D riskinde 3 kat artış saptanmıştır.
Dünyada 25 yaş ve üzeri bireylerin yaklaşık \%40’ında hipertansiyon olduğu, 2015 yılında bir milyar kişiye ulaştığı ve hızla artmaya da devam ettiği rapor edilmiştir. Hipertansiyonun prematür $\mathrm{KVH}$ için en önemli risk etmeni olduğu ve küresel olarak tüm iskemik kalp hastalıkları ve inmelerin \%50'sinin nedeni olduğu bilinmektedir. Lineer-doz yanıt metaanalizinde, hipertansiyon riski ile ters ilişki $30 \mathrm{~g} /$ gün tam tahıl (RR: 0.92), 100 g/gün meyve (RR: 0.97), $28 \mathrm{~g} /$ gün sert kabuklu yemiş (RR: 0.70) ve $200 \mathrm{~g} / \mathrm{gün}$ süt ve ürünleri (RR: 0.95) tüketimi ile pozitif ilişki ise $100 \mathrm{~g} / \mathrm{gün}$ kırmızı et (RR: 1.14), $50 \mathrm{~g} / \mathrm{gün}$ işlenmiş et (RR: 1.12) ve $250 \mathrm{~mL} /$ gün şekerle tatlandırılmış içecek (RR: 1.07) tüketimi ile belirlenmiştir. Lineerolmayan ilişki ise tam tahıl, meyve, balık ve işlenmiş et ile hipertansiyon riski arasında bulunmuştur. $\mathrm{Bu}$ bulgular hipertansiyon riskinin önlenmesinde günümüz beslenme rehberlerini desteklemektedir (46).

Dünya'da kolorektal kanserler kadınlarda ikinci, erkeklerde üçüncü sırada en sık görülen kanser türüdür. 2012 yılında yaklaşık 694000 erkek ve kadının kolorektal kanseri nedeniyle öldüğü bilinmektedir (47). Etiyolojisi multifaktöreldir ve yaşam biçimi etmenleri diyetle birlikte kolorektal kanser için risk etmenidir ve diyet önlenmesinde (12 temel besin grubu) anahtardır. Lineer doz-yanıt meta-analizinde ilişkiler tam tahıl (RR 30g/gün: 0.95), sebze (RR $100 \mathrm{~g} /$ gün: 0.97), meyve (RR $100 \mathrm{~g} / \mathrm{gün:} \mathrm{0.97),} \mathrm{süt} \mathrm{ve} \mathrm{ürünleri}$ (RR 200 g/gün: 0.93) ile kırmızı et (RR 100g/gün: 1.12) ve işlenmiş et (RR 50 g/gün: 1.17) ile gözlenmiştir. Lineer olmayan ilişki ise, sebze, meyve, süt ve ürünleri ile belirlenmiştir. Sonuçta tam tahıl, sebze, meyve, süt ve ürünlerinin fazla tüketimi ve kırmızı et ile işlenmiş et ürünlerinin az tüketimi düşük kolorektal kanser riski ile ilintiyi göstermiştir (48).

\section{Diyetisyen ve Sürdürülebilir Beslenme}

Avrupa Diyetisyen Dernekleri Federasyonu (EFAD) sürdürülebilir diyetlerin sağlıklı toplumlar oluşturduğunu belirtmiştir (49). Diyetisyenler besin bilimi, toplum gereksinmeleri, davranış değiştirme ve insan sağlığını geliştirme alanlarında aldıkları eğitim 
ve uzmanlıkları nedeniyle toplumların sürdürülebilir beslenme örüntülerini yönlendirmede tek ve önemli meslek mensubudur. Diyetisyenler bu önemli görevi sürekli yürütme isteğinde olmalıdır. Sürdürülebilir beslenmenin toplumun sağlığı üzerinde etkisini bilen diyetisyenler sürdürülebilir besin sistemini Sürdürülebilir Kalkınma Hedefleri ve Paris Antlaşması ilkeleri doğrultusunda yerine getirme zorunluluğunda olmalıdır. Bu doğrultuda diyetisyenler;

- Herkes için yeterli, güvenilir, sağlıklı ve sürdürülebilir diyetleri yaşam döngüsü boyunca sağlamalı ve desteklemelidir.

- Ulusal Beslenme Rehberleri hazırlanırken sürdürülebilir beslenme örüntüsünü dikkate almalıdır.

- Besin ve Beslenme Plan ve Politikaları'nın oluşturulmasinda ve yürütülmesinde sürdürülebilir beslenmeyi hedefler arasında vurgulamalıdır.

- Besin zincirinde, toplu beslenme sistemleri alanında ve evlerde besin israfının ve kaybının önlenmesinde aktif rolünü güçlendirmeli ve halkın bilinçlendirilmesine ve eğitimine önem vermelidir (49).

Tüm bu yaklaşımları karşılayacak diyetisyenlerin mesleki eğitim ve öğretim programlarında sürdürülebilir beslenme, sürdürülebilir sağlık, sürdürülebilir çevre vd. yaklaşımlara yer verilmelidir. Diyetisyenler sağlıklı, sürdürülebilir diyetler konusunda etkin eğitim almalı, besin üretimi, fiyatlandırma gibi ülke politikalarını etkileme çabasında bulunabilmeli, varlıklarını görünür kılmalı, becerilerini pekiştirmeli ve sürdürülebilirlik okuryazarı ve savunucusu olmalıdır (50).

\section{SONUÇ}

Son yillarda sürdürülebilirlik, besin güvencesi ve beslenme uluslararası tartışma konusu olmuş, sürdürülebilir diyetler toplum sağllğı beslenmesinde önemli bir kavram haline gelmiş, sürdürülebilir besin sistemleri için de kritik bir konuya dönüşmüştür. Diyetisyenler sürdürülebilir beslenmenin temel savunucuları olmalı, mesleki eğitim ve öğretimlerinde sürdürülebilir beslenme, sürdürülebilir sağllk ve sürdürülebilir çevre kavramları yer almalıdır.

Ulusal Beslenme Rehberleri sürdürülebilirliği kapsamalıdır (50). Amerika Birleşik Devletleri 2015 Amerikalılar için Beslenme Önerileri, daha sonra da Katar, Brezilya, İsveç ve Hollanda ulusal beslenme rehberlerinde sürdürülebilirliği dikkate almıştır. Almanya Sürdürülebilir Kalkınma Konseyi ise tüketiciler için sürdürülebilir alışveriş sepeti rehberi yayınlamıştır (3).

Çıkar çatışması - Conflict of interest: Yazarlar çıkar çatışması olmadığını beyan ederler. - The authors declare that they have no conflict of interest.

\section{KAYNAKLAR}

1. FAO/WHO. Sustainable healthy diets - Guiding principles. Rome, 2019.

2. United Nations World Commission on Environment and Development, ed. Report of the World Commission on Environment and Development: Our Common Future. Oxford: Oxford University Press, 1987.

3. Dernini S, Berry EM, Serra-Majem L, La Vecchia C, Capone R, Medina FX, et al., on behalf of the Scientific Committee of the International Foundation of Mediterranean Diet. Med Diet 4.0: The sustainable Mediterranean diet with four benefits. PHN. 2017;20:7:1322-30.

4. Burlingame B, Dernini S. Sustainable diets and biodiversity. FAO, 2012.

5. Alexandratos N, Bruinsma J. World Agriculture Towards 2030/2050: The 2012 Revision. ESA Working Paper no. 12-03. Rome: FAO, 2012.

6. Willett W, Rockström J, Loken B, Springmann M, Lang T, Vermeulen S, et al. Food in the Anthropocene: the EATLancet Commission on healthy diets from sustainable food systems. Lancet. 2019;393:447-92.

7. Vermeulen SJ, Campbell BM, Ingram JSI. Climate change and food systems. Annu Rev Environ Resour. 2012; 37:195-222.

8. Foley JA1, Defries R, Asner GP, Barford C, Bonan G, Carpenter SR, et al. Global consequences of land use. Science. 2005;309:570-74.

9. Food and Agriculture Organization of the UN, International Fund for Agricultural Development, 
UNICEF, World Food Programme, WHO. The state of food security and nutrition in the world. Rome: Food and Agriculture Organization of the UN, 2018.

10. UN. Sustainable Development Goals. Available at: https://sustainable development.un.org/?menu=1300 Accessed September 13, 2017.

11. UNICEF, WHO, World Bank. Levels and trends in child malnutrition: joint child malnutrition estimates. Washington, DC: World Health Organization, 2018.

12. WHO. Global report on diabetes. Geneva: World Health Organization, 2016.

13. NCD Risk Factor Collaboration (NCD-RisC). Worldwide trends in diabetes since 1980: a pooled analysis of 751 population-based studies with 4.4 million participants. Lancet. 2016;387:1513-30.

14. GBD 2017 Diet Collaborators. Health effects of dietary risks in 195 countries, 1990-2017: A systematic analysis for the Global Burden of Disease Study 2017. Lancet. 2019;393:1958-72.

15. Renzella J, Townsend N, Jewell J, Breda J, Roberts $\mathrm{N}$, Rayner $\mathrm{M}$, et al. What national and subnational interventions and policies based on Mediterranean and Nordic diets are recommended or implemented in the WHO European Region, and is there evidence of effectiveness in reducing noncommunicable diseases? Copenhagen: WHO Regional Office for Europe; 2018. Health Evidence Network (HEN) Synthesis Report No.:58

16. Bach-Faig A, Berry EM, Lairon D, Reguant J, Trichopoulou A, Dernini S, et al.; Mediterranean Diet Foundation Expert Group. Mediterranean diet pyramid today. Science and cultural updates. Public Health Nutr. 2011;14(12A):2274-84.

17. Sofi F, Abbate R, Gensini GF, Casini A. Accruing evidence on benefits of adherence to the Mediterranean diet on health: an updated systematic review and metaanalysis. Am J Clin Nutr. 2010;92(5):1189-96.

18. Sofi F, Cesari F, Abbate R, Gensini GF, Casini A. Adherence to Mediterranean diet and health status: meta-analysis. BMJ. 2008;337:a1344.

19. Schwingshackl L, Hoffmann G. Adherence to Mediterranean diet and risk of cancer: an updated systematic review and meta-analysis of observational studies. Cancer Med. 2015;4(12):1933-47.

20. Gonzalez CA, Riboli E. Diet and cancer prevention: contributions from the European Prospective Investigation into Cancer and Nutrition (EPIC) study. Eur J Cancer. 2010;46(14):2555-62.

21. Singh B, Parsaik AK, Mielke MM, Erwin PJ, Knopman DS, Petersen RC, et al. Association of Mediterranean diet with mild cognitive impairment and Alzheimer's disease: a systematic review and meta-analysis. J Alzheimers Dis. 2014;39(2):271-82.
22. Alcalay RN, Gu Y, Mejia-Santana H, Cote L, Marder KS, Scarmeas N. The association between Mediterranean diet adherence and Parkinson's disease. Mov Disord. 2012;27(6):771-4.

23. Grosso G, Mistretta A, Frigiola A, Gruttadauria S, Biondi A, Basile F, et al. Mediterranean diet and cardiovascular risk factors: a systematic review. Crit Rev Food Sci Nutr. 2014;54(5):593-610.

24. Estruch R, Ros E, Salas-Salvadó J, Covas M-I, Corella D, Arós F, et al. Primary prevention of cardiovascular disease with a Mediterranean diet. $\mathrm{N}$ Engl J Med. 2013;368(14):1279-90.

25. Tong TYN, Wareham NJ, Khaw KT, Imamura F, Forouhi NG. Prospective association of the Mediterranean diet with cardiovascular disease incidence and mortality and its population impact in a non-Mediterranean population: the EPIC-Norfolk study. BMC Med. 2016;14(1):135.

26. Salas-Salvadó J, Bulló M, Babio N, Martínez-González MÁ, Ibarrola-Jurado N, Basora J, et al. Reduction in the incidence of type 2 diabetes with the Mediterranean diet. Results of the PREDIMED-Reus nutrition intervention randomized trial. Diabetes Care. 2011;34(1):14-9.

27. García-Fernández E, Rico-Cabanas L, Rosgaard N, Estruch R, Bach-Faig A. Mediterranean diet and cardiodiabesity: a review. Nutrients. 2014;6(9):3474.

28. Esposito K, Maiorino MI, Ceriello A, Giugliano D. Prevention and control of type 2 diabetes by Mediterranean diet: a systematic review. Diabetes Res Clin Pract. 2010;89(2):97-102.

29. Esposito K, Maiorino MI, Ciotola M, DiPalo C,Scognamiglio P, Gicchino M. et al. Effects of a Mediterranean-style diet on the need for antihyperglycemic drug therapy in patients with newly diagnosed type 2 diabetes: a randomized trial. Ann Intern Med. 2009;151(5):306-14.

30. Shai I, Schwarzfuchs D, Henkin Y, Shahar DR, Witkow S, Greenberg I, et al. Weight loss with a low-carbohydrate, Mediterranean, or low-fat diet. $N$ Engl J Med. 2008;359(3):229-41.

31. Mithril C, Dragsted LO, Meyer C, Blauert E, Holt MK, Astrup A. Guidelines for the New Nordic Diet. Public Health Nutr. 2012;15(10):1941-7.

32. Kanerva N, Kaartinen NE, Rissanen H, Knekt P, Eriksson JG, Saaksjarvi K, et al. Associations of the Baltic Sea diet with cardiometabolic risk factors: a meta-analysis of three Finnish studies. Br J Nutr. 2014;112(4):616-26.

33. Kanerva N, Kaartinen NE, Schwab U, Lahti-Koski M, Männistö S. The Baltic Sea Diet Score: a tool for assessing healthy eating in Nordic countries. Public Health Nutr. 2014;17(8):1697-705.

34. Kanerva N, Rissanen H, Knekt P, Havulinna AS, Eriksson JG, Männistö S. The healthy Nordic diet and incidence 
of type 2 diabetes: 10-year follow-up. Diabetes Res Clin Pract. 2014;106(2):e34-7.

35. Uusitupa M, Hermansen K, Savolainen MJ, Schwab U, Kolehmainen M, Brader L, et al. Effects of an isocaloric healthy Nordic diet on insulin sensitivity, lipid profile and inflammation markers in metabolic syndrome: a randomized study (SYSDIET). J Intern Med. 2013;274(1):52-66.

36. Brader L, Uusitupa M, Dragsted LO, Hermansen K. Effects of an isocaloric healthy Nordic diet on ambulatory blood pressure in metabolic syndrome: a randomized SYSDIET substudy. Eur J Clin Nutr. 2014;68(1):57-63.

37. Adamsson V, Reumark A, Fredriksson IB, Hammarström E,VessbyB,JohanssonG, etal.EffectsofahealthyNordicdiet on cardiovascular risk factors in hypercholesterolaemic subjects: a randomized controlled trial (NORDIET). J Intern Med. 2011;269(2):150-9.

38. Lacoppidan SA, Kyrø C, Loft S, Helnæs A, Christensen J, Hansen CP, et al. Adherence to a healthy Nordic food index is associated with a lower risk of type-2 diabetes: the Danish Diet, Cancer and Health Cohort Study. Nutrients. 2015;7(10):8633-44.

39. Poulsen SK, Due A, Jordy AB, Kiens B, Stark KD, Stender $S$, et al. Health effect of the New Nordic Diet in adults with increased waist circumference: a 6-mo randomized controlled trial. Am J Clin Nutr. 2014;99(1):35-45.

40. Rockström J, Gaffney O, Rogelj J, Meinshausen M, Nakicenovic N, Schellnhuber HJ. A roadmap for rapid decarbonization. Science. 2017;355:1269-71.

41. Katz DL, Meller S. Can we say what diet is best for health? Annu. Rev. Public Health 2014;35:83-103.

42. Hirvonen K, Bai Y, Headey D, Masters WA. Affordability of the EAT-Lancet reference diet: a global analysis.
Lancet Glob Health. 2019; 1-8.

43. Schwingshackl L, Schwedhelm C, Hoffmann G, Lampousi AM, Knüppel S, Iqbal K,et al. Food groups and risk of allcause mortality: a systematic review and meta-analysis of prospective studies. Am J Clin Nutr. 2017;105:1462-73.

44. Bechthold A, Boeing H, Schwedhelm C, Hoffmann G, Knüppel S, Iqbal K, et al. Food groups and risk of coronary heart disease, stroke and heart failure: A systematic review and dose-response meta-analysis of prospective studies. Crit Rev Food Sci Nutr. 2019;59:7:1071-90.

45. Schwingshackl L, Hoffmann G, Lampousi AM, Knüppel S, Iqbal K, Schwedhelm C, et al. Food groups and risk of type 2 diabetes mellitus: a systematic review and meta-analysis of prospective studies. Eur J Epidemiol. 2017;32:363-75.

46. Schwingshackl L, Schwedhelm C, Hoffmann G, Knüppel $\mathrm{S}$, Iqbal K, Andriolo V, et al. Food groups and risk of hypertension: A systematic review and dose-response meta-analysis of prospective studies. Adv Nutr. 2017;8:793-803.

47. Ferlay J, Soerjomataram I, Dikshit R, Eser S, Mathers C, Rebelo M, et al. Cancer incidence and mortality worldwide: sources, methods and major patterns in GLOBOCAN 2012. Int J Cancer. 2015;136:E359-E86.

48. Schwingshackl L, Schwedhelm C, Hoffmann G, Kn€uppel $\mathrm{S}$, Preterre AL, Iqbal K, et al. Food groups and risk of colorectal cancer. Int J Cancer. 2018;142:1748-58.

49. EFAD (The European Federation of the Associations of Dietitians). Sustainable Health Through the Life Span. 2019.

50. Pettinger C. Sustainable eating: Opportunities for nutrition professionals. Nutr Bull. 2018;43:226-37. 